\title{
Effect of Oxalic Acid on Rice Husk
}

\author{
Olawale $\mathrm{O}^{1}$, Oyawale, F.A, ${ }^{2}$ Makinde, O.W ${ }^{3}$ and Ogundele, K.T ${ }^{4}$ \\ ${ }^{1,2}$ Industrial and Production Engineering Department,University of Ibadan, Nigeria. \\ ${ }^{3,4}$ Environmental and Earth Sciences Division, Center for Energy Research and Development, O.A.U, \\ Ife, Nigeria \\ DOI: 10.6088/ijaser.0020101067
}

\begin{abstract}
The aim of this research is to determine the effect of Oxalic acid on rice husk. Rice husk was collected from Osun State, Nigeria. Two methods of rice husk namely: Raw rice husk (RRH) and Leached rice husk (LRH) were subjected to thermal treatment at $7000 \mathrm{C}$ by varying the combustion time of $1-6 \mathrm{~h}$ to determine the effect of time on the type of silica produced. The treated and untreated rice husks ash was then analysed by X-Ray Diffraction (XRD) and Scanning Electron Microscope (SEM). Favourable results were obtained from XRD patterns at $3 \mathrm{~h}$ indicated that oxalic acid treated rice husk ash (LRHA) produced amorphous silica of good quality. However, specific surface area of the particle analysis at $3 \mathrm{~h}$, indicated the highest amount of $16.82 \mathrm{~mm} 2 / \mathrm{g}$ and also the SEM presented appropriated morphological characteristics of the best silica.
\end{abstract}

Keywords: Rice husk, Oxalic Acid, Specific Surface Area, XRD, Amorphous Silica, Oxalic Acid, Characterisation, Leaching.

\section{Introduction}

Rice husk (RH) is one of the main agricultural disposals in the rice-producing countries. According to the newest statistical data of the Food and Agriculture Organization (FAO, 2009) the annual paddy production of the 20 largest rice-producing countries amounts to 616 million tons (Xiong et al 2009). Industrial importance of rice husk ( $\mathrm{RH})$ is due to the presence of silica in hydrated amorphous form. Rice husk on burning gives $14-20 \%$ ash which contains $80-95 \%$ silica in the crystalline form and minor amounts of metallic elements Umeda and Kondoh, 2008).By controlling the burning conditions like temperature and time, amorphous silica of ultrafine size and reactivity can be produced. Pre-treatment of the husk with mineral acids followed by controlled ashing gives silica with high purity (Chandrasker et al 2005). When rice husk is burnt, approximately one fifth of the original weight is obtained as a by-product (Amutha et al 2010). Rice husks ashes are needed to generate favourable structure and desirable properties. For example, amorphous structure, high specific surface area (SSA), large pore volume (PV) and high reactivity are very important (SouZa et al 2002; Umeda and Kondoh, 2008).

The most important property of Rice husk ash (RHA) that determines the pozzolanic activity is its amorphous phase content (Armesto et al 2002). Combustion is the conventional technique for rice husk (RH) to exploit the calorific value and to obtain silica for commercial use, but such cations as $\mathrm{K}^{+}, \mathrm{Al}^{3+}, \mathrm{P}^{5+}, \mathrm{Fe}^{3+}$, and $\mathrm{Mn}^{+}$can remain in rice husk ash (RHA) as oxides, decreasing the purity of RHA and further limiting its use. Moreover, in the direct combustion process of RH, the obtained RHA consists of many black particles, which are very difficult to be fully burned off (Xiong et al 2009).The high impurity $\mathrm{K}$ content is generally recognized to be the cause for this phenomenon

*Corresponding author (e-mail: lamstock2@yahoo.com) 
(Krishnarao et al 2005). According to Umeda and Kondoh (2008), treatment of rice husk with oxalic acid remove the impurities present in it and high percentage of silica will be extracted from it. In this study, the presence of amorphous silica in RHA obtained at time range 1-6h was examined by $\mathrm{X}$-ray Diffraction (XRD). The microstructure of the best silica was also observed.

The objectives towards this research are:

i. To determine Chemical constituents and specific surface area

ii. To determine the best amorphous silica from both raw rice husk and leached rice husk and

iii. To determine the microstructure of the best silica

\section{Materials and Experimental Procedures}

\subsection{Raw Materials}

Rice Husk (RH) samples were collected from the same area. The first process (RRH) was cleaned, then ground and sieved to the diameter of $0.075 \mathrm{~mm}$.The second process (LRH) was doubly-washed with distilled water thoroughly to remove adhering soil and dust. Then, the rice husk mixed with 1 molar of Oxalic Acid was put in a glass beaker placed on hot plate at $90^{\circ} \mathrm{C}$ for 1 hour. It was cooled and kept intact for 20 hours. The supernatant liquid was decanted and then washed thoroughly with distilled water for 5 times so as to remove the oxalic acid completely. The leached rice husks were dried in an oven at $110^{\circ} \mathrm{C}$ for $24 \mathrm{~h}$.

The leached husk was dried at $105 \mathrm{C}$ for 24 hours, cooled in desiccator, then ground and sieved to the diameter of lower than $0.075 \mathrm{~mm}$, and stored in the desiccator. Rice Husk Ash (RHA) was prepared. Producing pure and active silica from RHA a thermal treatment at calcination temperature of $700^{\circ} \mathrm{C}$ was used and held at these temperature for $1-6 \mathrm{~h}$ in batch process separately. The aim of this calcinations step is to increase the relative amount of silica by reduction of carbonaceous materials present in the sample as well as to burn out other undesirable component. Heating cycles were carried out in an electric oven with a heating rate of $10^{\circ} \mathrm{C} / \mathrm{min}$. The samples were cooled down inside the oven then silica was extracted .This procedure was for the two methods.

\subsection{Sample Characterization and Analysis}

Several samples with different mole ratios of $\mathrm{NaCl} / \mathrm{SiO}_{2}$ were investigated with XRD. The XRD patterns in this step showed different peak intensities; this observation showed that varying the temperature led to great porous volume in silica network and the $\mathrm{NaCl}$ or hydrated lattice of this salt could be formed both inside and also outside of porous silica which made different peaks in XRD patterns in different intensities at different time of calcination, since, perturbations in the framework structure, crystal morphology, extra framework material, phase purity, crystallite size, and the setting and occupation of cation sites, and cation types can produce differences in the XRD spectra. The specific surface area (SSA) was determined using ASTMD626.The rice husk was also visually inspected when it reached the set time. $\mathrm{SiO}_{2}$ was estimated gravimetrically by $\mathrm{HF}$ evaporation method, $\mathrm{Na}_{2} \mathrm{O}$ and $\mathrm{K}_{2} \mathrm{O}$ by flame photometer, $\mathrm{Fe}_{2} \mathrm{O}_{3}$ by colorimetry using a UV-Visible spectrophotometer and other trace elements by atomic absorption spectrometer (AAS). 


\section{Results and Discussion}

Acid treated proved to be effective in removing some impurities to a lower level. Among the metallic elements, $\mathrm{Fe}_{2} \mathrm{O}_{3}$ reduced from $0.15 \mathrm{wt} \%$ in RRHA at $1 \mathrm{~h}$ to 0 at $6 \mathrm{~h}, \mathrm{Na}_{2} \mathrm{O}$ reduced from $1.31 \mathrm{wt} \%$ to $0.03 \mathrm{wt} \%$ and also $\mathrm{K}_{2} \mathrm{O}$ from $1.5 \mathrm{wt} \%$ to $0.02 \mathrm{wt} \%$.

\subsection{Research Findings}

This result correlated with what was stated in literature that: 'Rice Husk Ash contains over $80 \%$ of silica and a small proportion of impurities such as $\mathrm{K}_{2} \mathrm{O}, \mathrm{Na}_{2} \mathrm{O}$ and $\mathrm{Fe}_{2} \mathrm{O}_{3}$ can be removed by acid leaching' (Amutha et al 2010).XRD of RRHA at 3h of calcination is shown in figure 2 while for LRHA is shown in Figure 4. RRHA at $3 \mathrm{~h}$ of combustion was crystalline, thus it was not considered since the objective is to get amorphous silica. Table 1 shows the chemical constituents of both raw and leached rice husk ashes. Compare the acid-treated samples, treatment of the samples with acid proved to be effective in removing some metals to a lower level and some are completely removed after $6 \mathrm{~h}$ of calcination. Among the metallic element, the percentage of $\mathrm{K}_{2} \mathrm{O}$ is highest which is 1.500 wt \% was reduced to 0.02 and $\mathrm{Na}_{2} \mathrm{O}$ reduced from 1.310 to $0.03 \%$ at the end of $6 \mathrm{~h}$ of calcination. The amount of silica increased in leached rice husk ashes of each of the processes. Specific Surface Area of the particles increased from raw rice husk ash from $16.14 \mathrm{~mm}^{2} / \mathrm{g}$ to $16.82 \mathrm{~mm}^{2} / \mathrm{g}$ in Leached rice husk ash at $3 \mathrm{~h}$ of burning. The XRD results of calcination time from 1-6 $\mathrm{h}$ are shown in Figures1-6.The SEM of the best silica is also given in Figure 1.

Observations from calcination temperature of $700^{\circ} \mathrm{C}$ and time varied from $1-6 \mathrm{~h}$ are stated below: 1h (hour) of calcination: $100 \%$ grey colour was observed

$2 \mathrm{~h}$ of calcination: significant change of greyish of $25 \%$ and $75 \%$ dull white colour was observed 3h of calcination: completely dull white colour was observed 4h of calcination: there was significant change of $50 \%$ dull white and $50 \%$ white colour $5 \mathrm{~h}$ of calcination significant change of $80 \%$ white ash and $20 \%$ dull white 6h of calcination: $100 \%$ white ash was observed

Significant effects were noted at $1 \mathrm{~h}, 3 \mathrm{~h}$ and $6 \mathrm{~h}$ of calcinations temperature of $700^{\circ} \mathrm{C}$, which were used for the XRD results. The best XRD was used for the SEM.

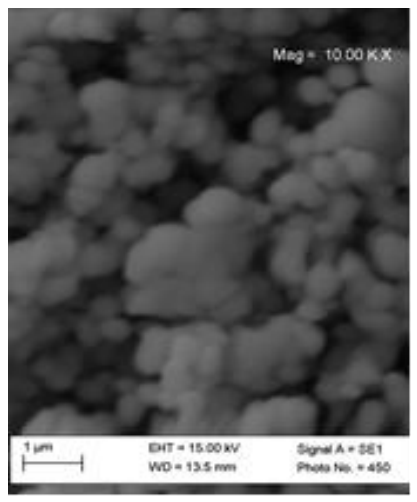

Figure 1: SEM of the Silica at 3h 
Table 1: chemical constituents of both raw and leached rice husk ashes

\begin{tabular}{|l|l|l|l|l|l|l|}
\hline $700{ }^{\circ} \mathrm{C}$ & $\begin{array}{l}\mathrm{h} \\
\mathrm{RRHA}\end{array}$ & $\begin{array}{l}\mathrm{h} \\
\mathrm{LRH} \\
\mathrm{A}\end{array}$ & $\begin{array}{l}3 \mathrm{~h} \\
\mathrm{RRH} \\
\mathrm{A}\end{array}$ & $\begin{array}{l}\text { Lh } \\
\mathrm{LRH} \\
\mathrm{A}\end{array}$ & $\begin{array}{l}6 \mathrm{~h} \\
\mathrm{RRH} \\
\mathrm{A}\end{array}$ & $\begin{array}{l}\text { LRH } \\
\text { A }\end{array}$ \\
\hline $\mathrm{SiO}_{2}(\%)$ & 86.780 & 89.87 & 89.16 & 91.26 & 88.74 & $\begin{array}{l}89.92 \\
0\end{array}$ \\
\hline $\mathrm{Fe}_{2} \mathrm{O}_{3}(\%)$ & 0.150 & 0.120 & 0.120 & 0.030 & 0.000 & 0.000 \\
\hline $\mathrm{Zn}(\%)$ & 0.040 & 0.030 & 0.020 & 0.000 & 0.002 & 0.016 \\
\hline $\mathrm{Mn}(\%)$ & 0.016 & 0.013 & 0.040 & 0.000 & 0.010 & 0.003 \\
\hline $\mathrm{CaO}(\%)$ & 0.100 & 0.100 & 0.150 & 0.070 & 0.110 & 0.050 \\
\hline $\mathrm{MgO}(\%)$ & 0.730 & 0.950 & 1.070 & 0.600 & 0.850 & 0.320 \\
\hline $\mathrm{Na}_{2} \mathrm{O}(\%)$ & 1.310 & 0.880 & 1.020 & 0.350 & 1.260 & 0.030 \\
\hline $\mathrm{K}_{2} \mathrm{O}(\%)$ & 1.500 & 0.320 & 1.250 & 0.260 & 0.330 & 0.020 \\
\hline $\begin{array}{l}\mathrm{SSA} \\
(\mathrm{mm} / \mathrm{g})\end{array}$ & 16.14 & 14.38 & 16.34 & 16.82 & 12.67 & 15.89 \\
\hline
\end{tabular}

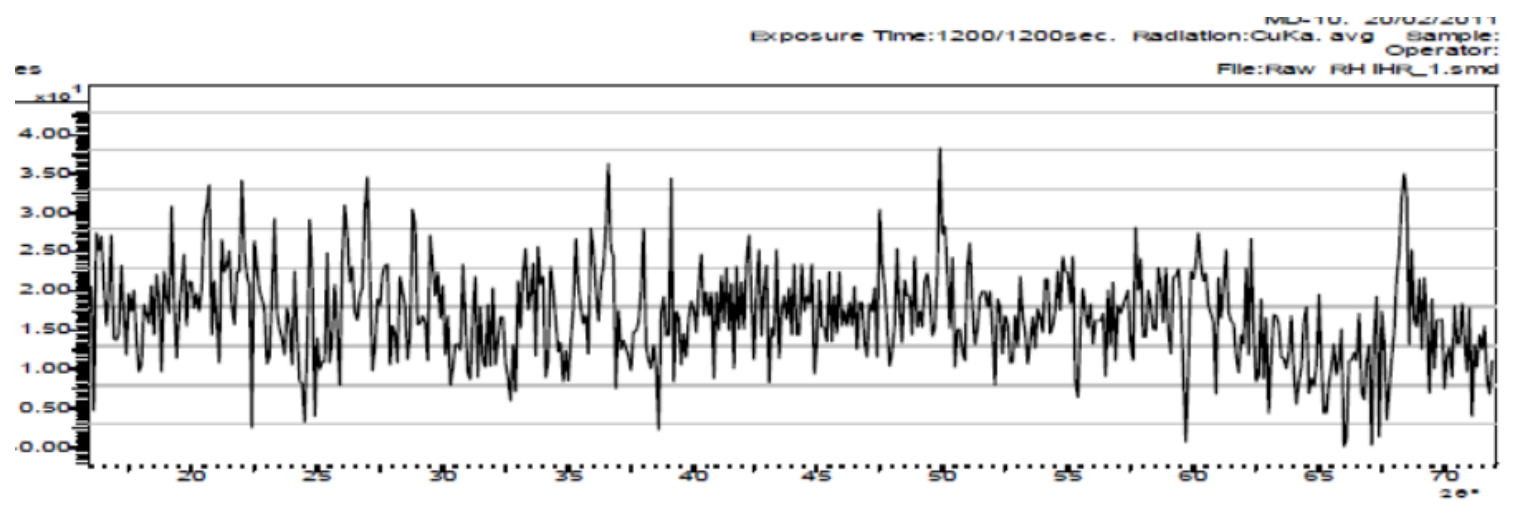

Figure 1: XRD of Raw Rice Husk Ash at $1 \mathrm{~h}$

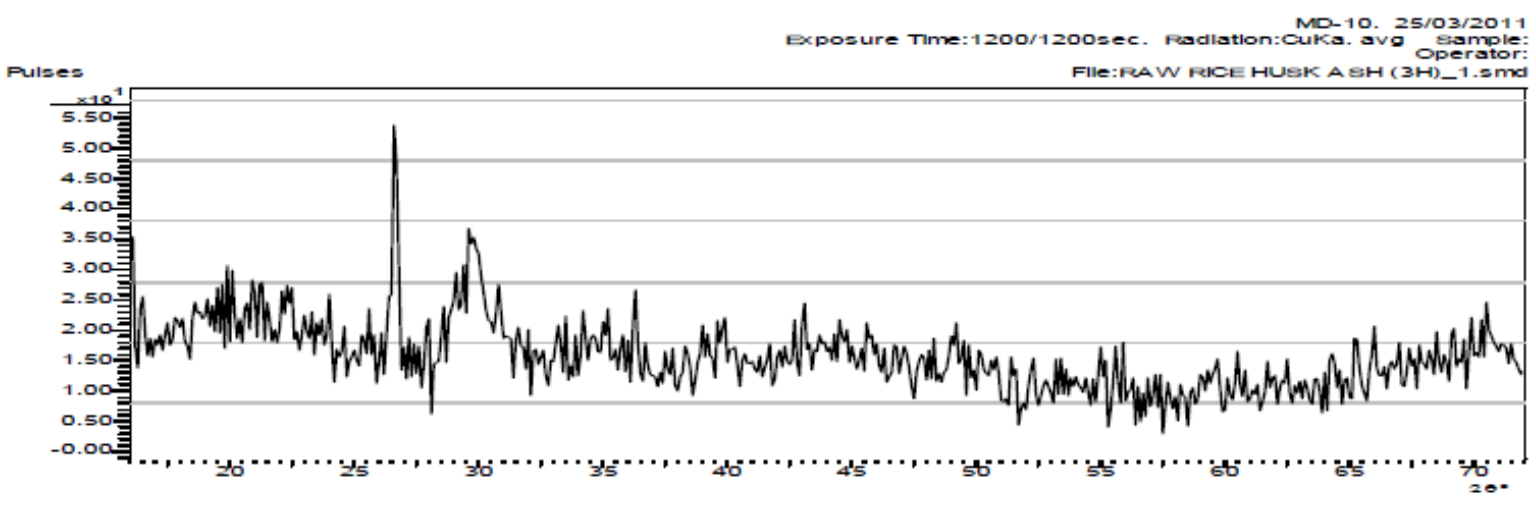

Figure 2: XRD of Raw Rice Husk Ash at 3h 


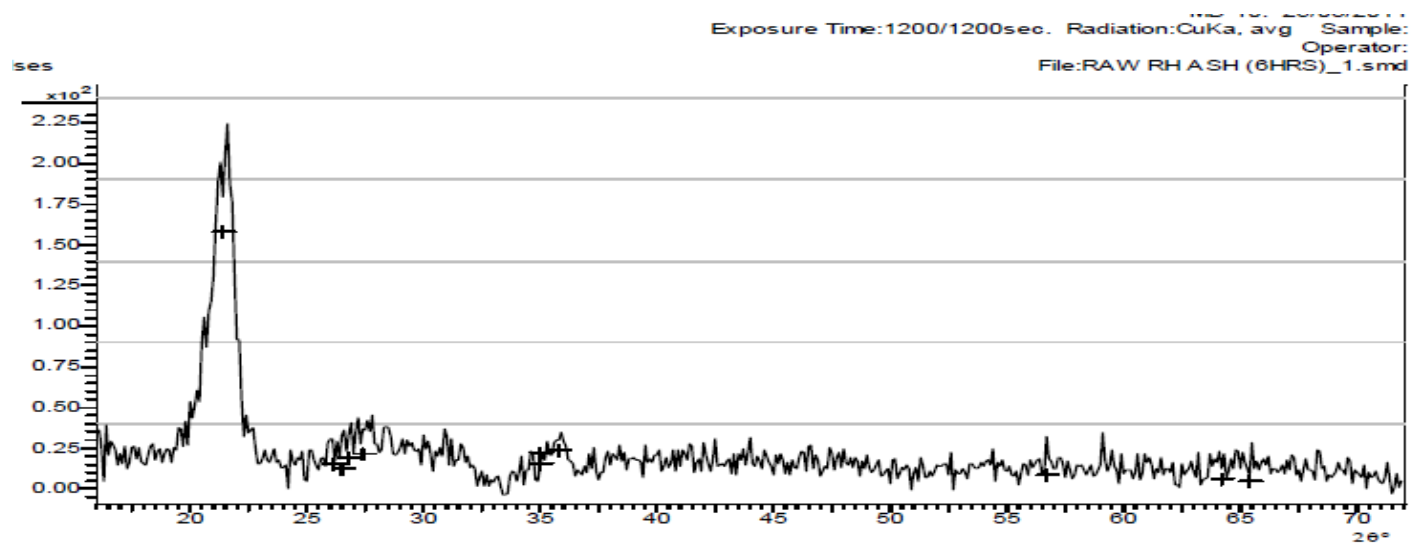

Figure 3: XRD of RRHA at $6 \mathrm{~h}$

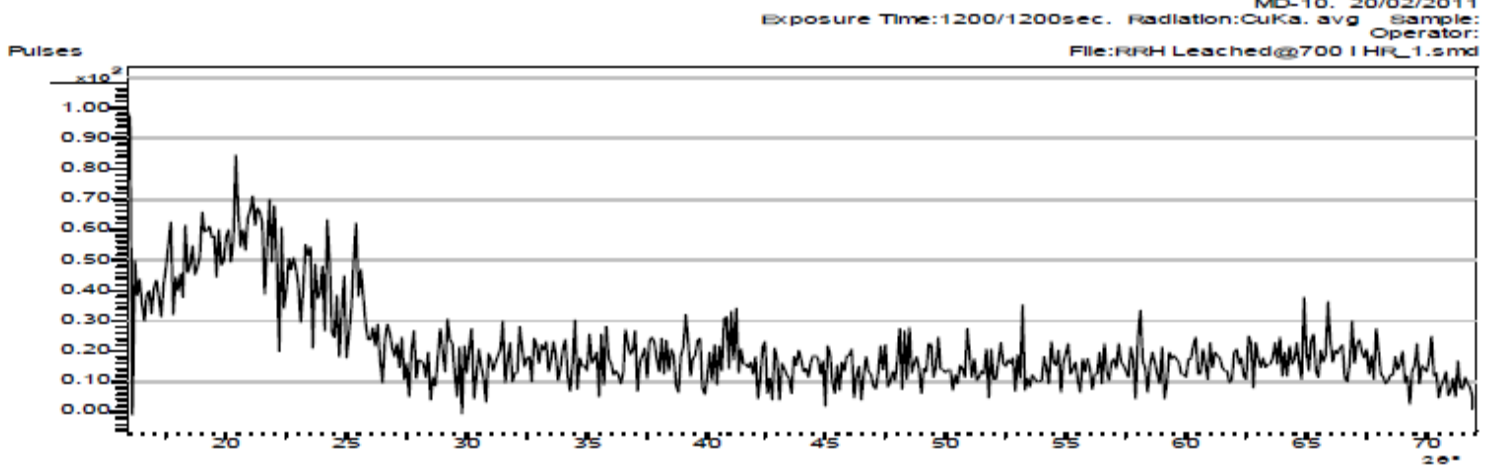

Figure 4: XRD of LRHA at $1 \mathrm{~h}$

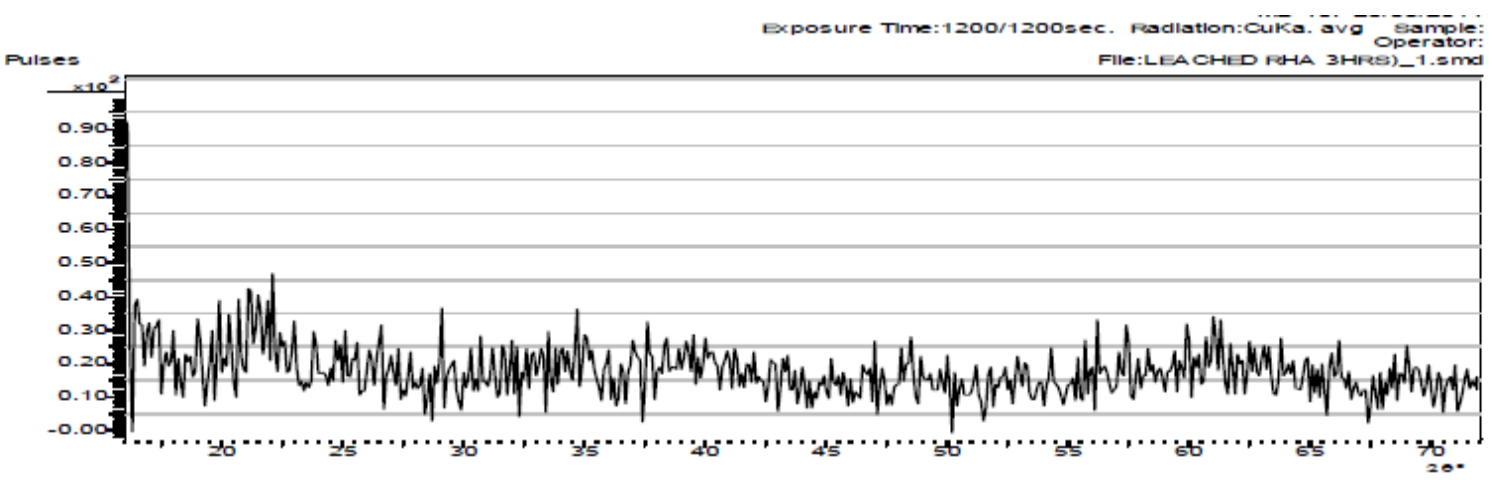

Figure 5: XRD of LRHA at 3h

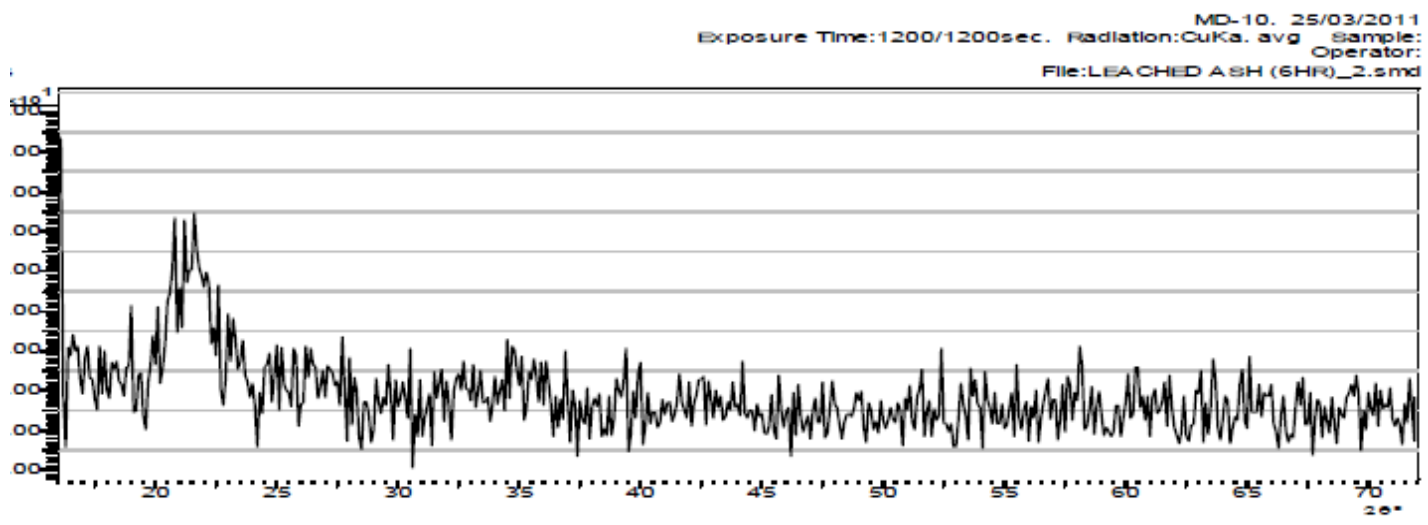

Figure 6: XRD of LRHA at $6 \mathrm{~h}$ 


\section{Acknowledgements}

We thank the entire management and staff of Industrial and Production Engineering, University of Ibadan

\section{Conclusion}

In this study, a chemical constituent of rice husk was determined using AAS. Heat treating at $700^{\circ} \mathrm{C}$ for 6hour, complete combustion took place. This indicates that all carbon present was removed and an amorphous silica white ash was produced. From XRD, it shows that acid does not affect the amorphous nature of the silica. Therefore, the leaching procedure and the short calcination time of $3 \mathrm{~h}$ gave the highest specific surfaced area which was also the most active amorphous silica from the rice husk.

\section{References}

1. Armesto, L.; Bahillo, A.; Veijonen, K.; Cabanillas, A. and Otero, J. (2002). Combustion Behaviour of Rice Husk in a Bubbling Fluidised Bed. Biomass and Bioenergy. 23,171-179.

2. Unesp - São (2008). Comparative studies between the rice husk ash (RHA) amorphous and crystalline Paulo State University. Journal Payá. Materials Compuestos (5),1-8Unidad de Investigación en Ciencia.

3. Amutha,K.;Ravibaskar,R. and Sivakumar,G (2010). Extraction, synthesis and characterization of nanosilica from rice husk ash. International Journal of nanotechnology and Application. 4(1), 61-66.ISBN:0973-631X.

4. ASTM D626 (1997). American Standard Test Methods Units' Micrometric estimation of specific surface area in crystalline granules.

5. Chandrasekhar, S, Pramada, P.N; and Praveen, L (2005). Effect of organic acid treatment on the properties of rice husk silica. Journal of Material Science.40, 6535-6544.

6. FAO (2009). Food and agricultural commodities production. http://faostat.fao.org/site/339/ default.aspx

7. Krishnarao, R.V., Subrahmanyam, J. and Jagadish Kumar, T. (2001).Studies on the formation of black particles in rice husk silica ash. Journal of European Ceramic Society. 21(1), 99-104.

8. Souza,M.F.;Magalhages, W.L.E and Persegil, M.C(2002)'Silica derived from burned rice hull'Materail.Science.5(4),467-474.ISSN:1516-1439

9. Umeda, J and Kondoh, K. (2008). Highly-purity amorphous silica originated in rice husks via carboxylic acid leaching process. Journal of Material Science 43(22), 7084-7090.

10. Xiong, Liangming*,Saito Kazuya , Sekiya Edson H, Sujaridworakuni Pornapa and Wada Shigetaka (2009). Influence of Impurity Ions on Rice Husk Combustion. Journal of Metals, Materials and Minerals. 19(2), 73-77. 